\title{
Theory without Theories: Well-Being, Ethics, and Medicine
}

Jennifer Hawkins

Duke University

There is no concept more important for clear thinking about medical ethics than the concept of well-being or (what I take to be the same thing) the concept of what's good for a person. Yet for a variety of reasons medical ethicists have generally had little to say about this notion and have tended not to engage much with the philosophical literature on this topic. A brief look at the many textbooks available for teaching medical ethics to both pre-med and medical students reveals that almost none of them deal with this topic. ${ }^{1}$ And a review of the bioethics scholarly literature reveals that the topic is not often discussed there. ${ }^{2}$ Even the chapter devoted to the principle of beneficence in Beauchamp and Childress's Principles of

1 To substantiate this claim, I borrow a move from David DeGrazia (1995). He argued some time ago that bioethicists rarely pay attention to the philosophy of well-being either in scholarship or teaching. To document this he examined the most prominent bioethics textbooks at the time and found no philosophical discussion of well-being. Borrowing his strategy, I have looked at most of the current popular textbooks and I have also found that none of them discuss well-being. The nine books I examined are included in the list of references and have a ${ }^{* *}$ after the entry.

2 Bioethics journals tend to be catalogued in databases of philosophy as well as databases of medicine. When I search terms like "well-being," "welfare," or "best interests" on philosophy databases, I find mostly papers about well-being with no connection to medicine. Searching the same terms in medical databases mostly brings up either medical articles that use one of these terms in passing, or empirical studies of particular patient groups self-reporting how they feel about their lives. Only a tiny percent of articles or monographs analyze well-being or use more sophisticated analyses of well-being in making ethical arguments. There are, of course, exceptions to the rule. Here I am merely documenting a trend. 
Biomedical Ethics-arguably one of the most influential medical ethics textsdoesn't try to analyze welfare at all or even consider how welfare values relate to medical values. ${ }^{3}$

Of course, I realize that the practical day-to-day world of medicine is full of discussions of well-being, best interests, and quality of life, and no doubt some of these discussions are sophisticated and probing. But I remain convinced that medical ethics education would be much better if students were taught to think in a more substantial and structured way about well-being. And for that to happen medical ethicists must first adopt a more substantial and structured way of thinking about well-being.

Nonetheless, it is not at all obvious how to bring this about. Many philosophers, presented with such a problem, would think it appropriate to simply add some basic material on the philosophy of well-being, most likely an exposition of three standard types of well-being theory ("the big three"): hedonism, desire theories and objective list theories (Griffin 1986; Parfit 1984). However, my own experience over time has led me to the conclusion that standard philosophical approaches to the theory of well-being are of almost no use in the context of teaching practical ethics. But if we want to teach people to approach the topic in a more sophisticated way, and if the traditional philosophical theories are useless,

\footnotetext{
${ }^{3}$ Originally published in 1979 it is now in its 7th edition.
} 
what are we to do? How should we think about welfare in the practical medical ethics context? And why suppose that philosophy has anything to offer us on this front (given that, as I claim, its standard material on this topic is not useful)?

Over time I have developed an approach which is philosophically informed yet avoids discussion of the big three theories. It is what I think of as the "theorywithout-theories" approach to teaching, thinking and writing about well-being in practical ethical contexts. ${ }^{4}$ It has two elements. First is a focus on examining important and relatively uncontroversial constituents of welfare. These elements can be introduced and their nature questioned and probed without invoking general theories. The second key element is a framework for thinking about choice in relation to welfare, a framework that I refer to as "the mild objectivity framework."

\footnotetext{
4 Anna Alexandrova (2017) has recently argued that philosophy should devote more attention to developing what she calls "mid-level theories of welfare." There are real and important parallels between her concerns and mine. For example, we both agree that general philosophical theories are incredibly hard to relate to real life and that something else is therefore needed. Indeed, from a certain standpoint, I could be viewed as offering here a mid-level theory of welfare for medical ethics. Still, there are differences. Alexandrova emphasizes the need to develop mid-level theories of wellbeing for specific populations or groups of people, for example, children, or poor single mothers. My approach here, however, has been to develop a mid-level theory for a certain kind of context, namely the doctor-patient clinical context. Alexandrova also believes there is no single concept of welfare and no single real world phenomenon that such a concept, if it existed, could track. I believe, however, that there is both a single concept and a single phenomenon for which we are seeking to develop theories. It is only because certain constructs or simplifications "get it right" often enough that we view them as useful substitutes in certain contexts for the more complicated and controversial reality. That is the spirit in which my framework is offered. I believe it will "get it right" often enough to be incredibly useful, even though to use it we do not have to settle deeper philosophical debates. See also Hawkins (2019c).
} 
In what follows, I aim to convince readers, first, that the standard philosophical approach will not work in the practical context, and second, that the theory-withouttheories approach will. After a brief review of some basic terrain in $\S 1$, I turn in $\S 2$ to explaining why I find the standard philosophical approaches so unhelpful. §3 is then devoted to laying out the elements of the theory-without-theory approach and illustrating its usefulness with examples.

I am well aware that I have, so to speak, presented myself with quite the argumentative challenge, for there are critics from very different camps to convince. Many bioethicists remain deeply skeptical of the relevance of thinking in depth about well-being, and perhaps even more skeptical about introducing philosophical theories. If these readers focus exclusively on the arguments of $\S 2$, they may conclude that I have made their case for them: philosophical work on well-being has nothing to contribute. The challenge here is to convince these readers that the ideas canvassed in $\S 3$ are both substantive and useful. Many philosophers, on the other hand, will no doubt think I am selling philosophy short, and that I have excluded far too much. They may wish to take issue with my claims in $\S 2$. The challenge here is to convince them that giving up on a certain type of theory in the practical sphere is not giving up on theory altogether. In short, one group may wish to eliminate theoretical discussions of welfare altogether, seeing them as useless, while a different group may accept the value of such discussions but wish to conduct them quite differently, namely, by returning to a theory-based approach. The trick then is to convince people that the theory-without-theories approach really can help to 
improve thinking about important medical ethics cases, and can do so better than standard philosophical approaches.

\section{\$1.0 Preliminaries}

It is important to identify here at the outset the precise concept we are talking about. Philosophers struggle with terminology in this domain, because the English words traditionally used in philosophy have developed a very different set of meanings outside the discipline, which then cause confusion when philosophers introduce them into discussions aimed at a broader audience. For example, philosophers primarily talk about "well-being" or less commonly "welfare," but in ordinary English (at least in the U.S.) "well-being" has come to be largely synonymous with a holistic concept of health. This is problematic because health is much narrower than what philosophers wish to discuss. Indeed, part of what needs to be strongly emphasized in the medical context is the extent to which things beyond health (and beyond medical values generally) need to be considered when significant decisions are made. Philosophers who discuss well-being are discussing what it is that makes a life overall good for the person living it. Obviously many things contribute to the goodness of a life beyond health. Still, although problematic in this way, it is not clear that any other term is significantly better and so I shall, with some trepidation, stick to it and its close cousin "welfare."

It is also important to identify, even if only briefly, some of the untutored assumptions about well-being that are common, but which cause problems when we try to use them to think critically about patient choice in medical contexts. There are at least three worth identifying precisely so we can set them aside. The first is 
welfare nihilism, the claim that there simply are no facts about what is good or bad for people, and so nothing for others to theorize about. Such claims are common among students, and in my experience typically emerge in response to difficult cases, where it is hard for anyone to know what would be best. However, I seriously doubt that most of the people who say such things really believe them. After all, I doubt they would be tempted in their own case to approach an important life choice by simply flipping a coin—an approach that makes perfect sense if there really are no answers or if all answers are equal.

Espousal of welfare nihilism is also sometimes motivated by a general desire to avoid seeming paternalistic, as if just talking about what might be good for someone (other than oneself) is problematic. However, despite what some students initially assume, conversations with patients about their welfare are not morally problematic, nor is it wrong if occasionally, and on the basis of good reasons, a doctor seeks to rationally persuade a patient to change his mind for the patient's own good. Conversations must be respectful, and ultimate choice must lie with the patient, but provided these constraints are met, conversation is a good thing, not bad. ${ }^{5}$

\footnotetext{
5 There is evidence in the medical literature that not only students, but clinicians often fall into the trap of thinking that offering opinions about what would be best is objectionably paternalistic. For example, Savulescu (1995) rejects what he calls the "the fact-provider" view of the role of physicians which he claims became popular because it was viewed as most consistent with avoiding paternalism. Instead, he argues in favor of having doctors make substantive value judgments about what would be best overall for their patients, and he is careful to explain why this need not be morally objectionable. He reiterates these ideas in Savulescu (2007).
} 
A second common assumption is welfare medicalism, which is my label for the tendency to think about patient welfare in terms of purely medical values. It is the assumption that what is good for a patient is simply whatever is normally medically indicated in situations like the patient's. Medicine has a number of distinct values, as represented by the various goals it pursues: preventing illness, curing illness, managing symptoms in chronic illness when cure is not possible, extending life, restoring function that has been lost, preventing the loss of function, and relieving suffering (and this list is not exhaustive). In addition, medicine has typical ways of prioritizing among these values, ways that reflect long-standing medical experience and the preferences of a majority of patients. Thus it is often true that pursuing the medical value usually pursued in such situations (e.g. extending life), will in fact be best for the patient. But this is not always the case. Few people these days consciously embrace such a view, but many people nonetheless slip into this way of thinking in part because it is so often adequate, and in part because they are not sure how else to think about individual patient welfare. However, the discipline of bioethics was largely built on cases where what was best overall for the patient departed from medical norm. Clearly then, to address the most pressing cases we need a better way of thinking about the relationship between medical values and overall patient welfare.

By far the most common assumption about welfare in medical ethics is a simple version of welfare subjectivism. Indeed, insofar as the field can be said to possess any general framework for thinking about the relationship between medical values and welfare, this is it. Welfare subjectivism comes in two varieties. On the 
simplest version what is best for a person is for her to get what she currently most wants. This view leaves no room for error, making the subject infallible about her own good. A slightly more sophisticated version-welfare subjectivism*introduces a distinction between transient (usually emotionally based) desires, and more enduring values. The patient's welfare is then identified with receiving whatever these more stable values dictate. Welfare subjectivism* thus creates a little bit of room for cases in which what a person chooses is not really good for her. Still, only a very narrow kind of judgmental mistake is possible, and there is no room on either version of welfare subjectivism for the thought that getting what is dictated by her current values might not be good for a person.

As an example of the implicit assumption of welfare subjectivism* consider a oft-cited article by Dan Brock and Stephen Wartman (1990) entitled, "When Competent Patients Make Irrational Decisions." The authors note that even competent patients sometimes make poor choices, and they present their aim as that of helping clinicians identify such decisions. If clinicians can become better at recognizing poor choices, they will be more likely to try to persuade patients to make better ones. Although the language of 'better' and 'worse' is used throughout, the language of welfare is not. But it is natural to suppose that what makes a choice worrisome (and thus worthy of persuading a patient not to act on it) is that the choice goes against the patient's own interests, i.e. it is (relative to the available options) bad for the patient.

However, what Brock and Wartman rely on is the welfare subjectivist* distinction between transient desires and real values. Thus what they aim to help 
clinicians do is recognize cases where patients may be allowing temporary distractions or fears (e.g. fear of surgical procedures) to dictate choices that go against their own more enduring values. The whole framework suggests that the only kind of error possible when making medical choices is a kind of instrumental irrationality, a failure to get what one really wants. There is no recognition of the fact that in some cases, even if a patient gets what she wants, she may not be better off. And of course there is no discussion at all of what it really means to be better off.

This theme is taken up and amplified in a widely anthologized paper "Four Models of the Physician-Patient Relationship" (Emanuel and Emanuel 1992). The paper is about medical decision-making in the era of patient rights, and it is concerned with identifying the right balance between empowering patients to act on their values and helping patients to make good decisions. Once again, the natural assumption of readers would be that the aim of good decision-making is what is best for the patient from the welfare standpoint. But nowhere does the paper directly address this. The first model (the "paternalistic model") depicts the physician making decisions in accordance with welfare medicalism without consulting the patient's values and it is quickly set aside as ethically unsatisfactory. The second model (the "informative model") depicts a patient making decisions based purely on what she wants, but without much sense of how her values could be best realized by her medical options. It too is quickly set aside.

The third model (the "interpretive model") is one of two that the authors present as real candidates. But the interpretive model is just a more nuanced version of the informative model. It presents the doctor's goal as that of helping the 
patient identify her values and how to best realize those values given her medical options. Since success means that the patient realizes her current values this strongly suggests welfare subjectivism.* As with Brock and Wartman there is never any recognition in the article that a patient might get what she currently values and be no better off.

The final ("deliberative") model departs somewhat from the focus on patient values, but not in any way more likely to track patient welfare. The deliberative model builds on the interpretive model, requiring the physician to help the patient identify what will best promote her current values, but adding that physicians are also allowed to be advocates for certain medical values (e.g. not-smoking, weight loss) even if these values do not align with the patient's current values at all. The deliberative model is thus the only model (other than the decisively rejected paternalistic model) that suggests that a clinician might reasonably be allowed to advocate for something other than the patient's current values. But it is left mysterious why this should be permitted. Presumably the only reason a clinician would justifiably advocate for values that are not currently embraced by the patient would be if it genuinely seemed that pursuit of these new values would be better overall for the patient than pursuit of her currently held values. But this is never said. Thus the deliberative model remains unconvincing, since, as we know, medical values in themselves are not always good for patients, and no explicit link is drawn between advocating for medical values and the patient's overall welfare.

There are many, many other examples in the literature I could cite, but the point would be the same: medical ethicists often treat the project of helping patients 
make better choices as simply equivalent to helping them get what they really value. Welfare subjectivism* is implicit throughout much of the literature. But since it is clear that people sometimes get what they most want and are worse off for it (from their own perspective), this is not an adequate view. The popularity of this approach no doubt stems from the fact that a patient's values are clearly important. They are useful sources of information about the person, and in a fair number of cases they are reliable guides to what will benefit the person. But there are enough cases in medicine where this assumption fails that we need a better, more sophisticated framework for thinking about welfare.

To sum up: Welfare nihilism is false. Welfare medicalism, though part of the day-to-day culture of medicine, is at best a decision-making heuristic that delivers the right verdict in a limited number of cases. Welfare subjectivism, even in its slightly more sophisticated form, welfare subjectivism,* is also at best a kind of heuristic-useful in some cases and not at all in others. We can do better.

\section{\$2.0 Reconceiving the Topic Area}

The much better approach we need, however, is not to be found currently in the philosophical literature on well-being. Or so I wish to argue. For many years the canonical way to introduce the topic of well-being has been to introduce students to over-arching theories about the nature of well-being. And the canonical way to do this has been to start with a three-part division of theories derived from James Griffin (1986) and Derek Parfit (1984): hedonism, desire theories, and objective list theories, or "the big three." My claim, however, is that introducing these theories is 
unhelpful and should be abandoned for the purposes of doing practical ethics. There are various reasons for this, some quite general, having to do with the difficulty of helping students bridge the gap between theory and application, and some specific to the particular theories mentioned above.

The most general reason for not starting this way is that these theories are too abstract to be of much practical use. ${ }^{6}$ Thus in order to have them help us with practical ethical topics we need to do a lot of work-work that is both too complicated and too lengthy-before we can move ahead. Consider first that the simplest version of each theory faces numerous, well-known objections, most of which are quite powerful. We would not want to simply "apply" a simple version of any one of the big three-given how much agreement there is that the simple views are flawed. Of course, over time and in response to these objections many modifications have been proposed. But to avoid the simplistic versions and make use of these advances one must, almost as soon as each theory is presented, begin exploring the variety of ways of modifying it. Numerous theoretical choiceschoices that philosophers routinely agonize over-will have to be made before one can hope to move towards application. But that's not feasible for practical ethics.

Even once the initial theoretical decisions have been made, it is still true that many theories of well-being are incomplete in ways that hinder practical use. To

\footnotetext{
${ }^{6}$ Hall (2016) also argues that standard philosophical theories are of little use in practical ethics because of the difficulty of moving from theory to any kind of concrete decision. And also, like me, she points out that objective list theories typically fail to give us any guidance at all about how to make trade-offs between conflicting objective goods.
} 
give just one example, proponents of objective list theories rarely address the question of whether all or some of the items on the list are necessary for a good life (such that lack of an item makes a life much less good independently of how many other goods an individual has) or whether a good life simply requires that one have a certain number of goods from the list. Nor is it usually made clear how the items on the list are ranked, i.e. how good each item is in comparison to others. This matters, however, since real life forces us to make difficult choices, including sometimes choices between goods on the list. Perhaps a life with such a choice is not a great life, but we still want a theory to tell us which way forward is better, which choice is least bad.

Further problems arise when we ask ourselves how much of a particular good is appropriate for each person. It is all very well to say that friendship is an important good, but how many friends does a person need? Do we all need the same number? It seems plausible that we do not. A more subjectively oriented theorist might try to explain individual differences in terms of psychological differences (e.g. I am an introvert whereas you are an extrovert). But presumably an objective list theorist would not want to do that. Still, the question must be answered somehow if the theory is to be practically useful. Similar problems arise with respect to the other theories. In short, the task of moving from any one of the big three to practical choices is overwhelming. Better to start closer to the ground.

This is not a problem in traditional philosophy classes since usually no attempt is made there to answer practical questions. Instead, when well-being is discussed, the various theories are compared and time is spent considering various 
objections and replies, with the ultimate aim being to discover which theory is most likely true or which one seems overall best. In short, these are metaphysical conversations-very important metaphysical conversations-about what wellbeing most fundamentally is. There is definitely a place for such conversations in philosophy. But since we are unlikely to reach agreement on the fundamental metaphysics of well-being any time soon, and since these kinds of metaphysical discussions are not helpful in practice, what we need in practical ethics is something different.

It is also worth noting that many metaphysical details have little or no impact on practical decisions. To give just one example, hedonists maintain that happiness is the only intrinsic value, whereas other theories might say that happiness is intrinsically valuable but not the only such value, or that happiness is valuable in some other non-intrinsic way. But I am not aware of any theory that implies that happiness is unimportant. For example, desire theorists will only allow that happiness has intrinsic value if it is desired. But given the overwhelming empirical evidence that happiness is instrumentally important (Fredrickson 2001; Bishop 2014) - helping us to better achieve our goals whatever these are-even a desire theorist must grant that happiness matters practically. But if we can agree (or at least get much higher agreement) about the practical importance of happiness, then it is not really necessary to settle the precise kind of value at stake.

Nonetheless, many philosophers will still think that theories are worth a look, even if just to familiarize students with the different kinds of approaches. However, there are also quite specific reasons why each of the "big three" is 
unhelpful in a practical context. The case against objective list theories is the strongest, so I begin there. But as I will try to show there are good reasons to avoid all of them. ${ }^{7}$

\section{\$2.1 Setting Aside Objective Theories}

An objective list theory provides us with a list of (purportedly) intrinsic goods and claims that the goodness of these items for individuals does not depend in any way on the attitudes or feelings of the person whose welfare is in question (Parfit 1984, 493). ${ }^{8}$ If, for example, possessing knowledge is on the list of goods, then regardless of whether I want, value, or enjoy possessing knowledge the list theory claims that I am better off having it. Objective list theories so defined make two claims that are worth distinguishing: (1) the claim that our attitudes and/or feelings are not what makes something good, and (2) the claim that something could be good for us even if we have no positive reaction of any kind to it. As I see it, objective list theories should be left out of practically oriented discussions of welfare because their first

\footnotetext{
${ }^{7}$ Some readers may note that the following discussion of well-being theories does not go into much depth and rehearses certain objections that are extremely well known. However, it is important to remember the current aim. The aim is not to show that simple versions of these theories fail (something most philosophers already know), but to demonstrate that such theories are extremely unlikely to offer useful practical guidance.
}

8 Perfectionist theories were not discussed by Parfit or Griffin, but in recent years there has been renewed interest in perfectionism. However, all of the concerns I express about objective list theories apply equally to perfectionist theories. For an overview of perfectionist views of well-being see Bradford (2017). 
distinctive claim (about what makes something good for someone) is irrelevant for practical ethics and because their second distinctive claim (about there being no need for positive reactions on the part of the subject), though highly relevant, is far too controversial to be accepted on the basis of the thin justifications objective list theories can offer. ${ }^{9}$

The first claim—about what makes something good—is heatedly debated among philosophers and is really just a version of the ancient Euthyphro debate: is something good because we like it or value it, or do we like it or value it (assuming we do) because it is good? Is goodness created by our attitudes or is it entirely independent of them? Though it is an interesting question, it need not be answered before we do practical ethics. After all, if we can agree that some particular item X is good for a particular subject $\mathrm{S}$, and that $\mathrm{S}$ values or likes $\mathrm{X}$, then it hardly matters whether it is good because she likes it, or whether she likes it because it is good.

The second distinctive claim of objective list theorists is a rejection of what contemporary philosophers call "resonance," i.e. the idea that in order for something

\footnotetext{
${ }^{9}$ Like me, Haybron and Tiberius (2015) set aside objective theories, in their case within the realm of public policy. Their reasons, however, are rather different from mine. Their "pragmatic subjectivism" is based on the idea that respect for persons requires policy makers to remain neutral between theories of well-being and simply attend to what individuals see as good for themselves. So stated it seems perilously close to the simple equation of welfare with current values that I seek to challenge within the context of medicine. The difference may simply be that I focus on more intimate contexts and on decision-making for individuals. In these settings it is important to distinguish the before and after of decision-making-what a person believes will be good for her ex ante and what really is good for her ex post. Such distinctions don't figure much in their article, but this is probably because for the purposes of large-scale public policy, they aren't as important. Hall (2016) also rejects appeal to objective list theories in medicine, for reasons similar to Haybron and Tiberius.
} 
to be good for a person it must have some sort of positive psychological effect on the individual in question. Rejection of resonance is highly controversial, and indeed, is the reason most often given for rejecting objective list theories. Many people simply cannot fathom how something could be good for an individual if it does not now, and is unlikely ever in the future, to resonate with her in any way. Peter Railton's expression of this thought has by now become canonical: "It would be an intolerably alienated conception of someone's good to imagine that it might fail in any way to engage him" (Railton 1986, 9). And Shelly Kagan (2009) has expressed it forcefully in relation to objective list theories: "friends of an objective account of well-being seem forced to accept the unappealing claim that I could be extremely well off, provided that I have the right objective goods in my life, even though these things hold no appeal for me, and I am, in fact, utterly miserable."

It is important to recognize that resonance is not just a philosopher's metaphysical principle. In ordinary life, resonance plays an incredibly important epistemic role in judgments about what is good for an individual. This epistemic role is admittedly subtle. We do not (and should not) assume that resonance alone is indicative of personal goodness (though the fact that something resonates with someone may lead us to inquire further about its goodness or suitability for that person). Rather, the epistemic role of resonance is negative: those things that do not resonate at all are those we feel most certain are not good.

If we allow objective list theories to play a role in practical ethics, then we are in essence allowing that there may be cases where we are willing to say X is good for S despite complete lack of resonance. But it seems to me that if we throw out the 
resonance requirement, even for certain cases, we must have some other equally powerful epistemic indicator of what is or is not good for a particular individual and that the burden of producing such an indicator lies with the objective list theorist who wishes to employ his theory in the practical realm. Yet it is precisely in the realm of epistemic justification that objective list theories of welfare have been, traditionally, most vulnerable. At present, such views contain no satisfactory account of how we come to know that particular things are objectively good, and likewise no account of how we can reliably distinguish false goods from true ones. We have nothing more than the claims and assertions of different theorists who are drawn to the objective list account.

In response, a defender of objective list views might agree that we should not base real life practical decisions on unusual claims-items claimed to be good by only one version of list theory, or a version accepted by only a few theorists. But, it might be argued, certain items have appeared over and over again over time on most versions of list theories. That these items really are welfare goods is thus far more plausible, and this very fact of widespread acceptance can do the justificatory work.

However, when it comes to individual welfare, such an answer will not do. Welfare facts vary in subtle and not-so-subtle ways from person to person. What we need is not a reason to believe $\mathrm{X}$ is good for most people, but a reason to believe that $\mathrm{X}$ is good for a particular person at a particular time. And the challenging case we are considering is one where the person in question has no current positive reaction to $\mathrm{X}$ and, as best we can tell, is unlikely to develop any. One possible explanation for 
what is going on in such a case is that the objective list theory is true, $\mathrm{X}$ is indeed good for $\mathrm{S}$, and the lack of resonance is insignificant. But an equally plausible explanation is that objective list theory is false, $\mathrm{X}$ is not good for $\mathrm{S}$ and the lack of resonance is indicative of this. The surface plausibility of the claim that X is good for $\mathrm{S}$ also has two possible sources. It might stem from the fact that $\mathrm{X}$ is good for everyone or from the fact that $\mathrm{X}$ is good for many people in many situations. But if it stems from the second, we still have no basis for concluding it is good for S in this situation. The objective list theory lacks the resources to distinguish such cases. Such theorists in effect tell us to ignore one very powerful and widely accepted epistemic indicator (one that is saying this is not good for S) and yet fail to offer any other justification that can establish a positive link between $\mathrm{X}$ and $\mathrm{S}$. That is why it should be set-aside for practical purposes.

\section{§2.2 Setting Aside Desire Theories}

Desire theories of well-being equate what is good for a person with the satisfaction of her desires: it is good for you to get what you want. Desire theories come in several forms, but the primary problem stems from the fact that desire is generally understood to be a prospective attitude, by which I mean that desire is for something I do not yet have. In some cases, a desire for $\mathrm{X}$ will be satisfied almost as soon as it forms, ensuring that the time between desire formation and satisfaction is small. In other cases, I may desire something that I cannot hope to attain for a long time. The 
important point is simply that some temporal gap, whether large or small, always exists. ${ }^{10}$

Some theorists will respond that the theory need not, and indeed should not, be interpreted so narrowly because 'desire' need not be only prospective. Moreover, a theory limited to prospective attitudes would be implausible, since it would be unable to account for the value of unexpected benefits-"manna from heaven" as James Griffin puts it. (Griffin, 1986, 22). So we should take any reasonable version of desire theory to include both desires in the prospective sense as well as many occurrent attitudes. My point, however, is less about how we use the term 'desire' and more about problems that remain for any theory that includes prospective attitudes. As long as prospective attitudes remain a part of one's view, serious problems (of the sort described below) will continue to arise. And if one is willing to formulate a theory entirely in terms of occurrent attitudes then I see little reason to cling to the word "desire" (For surely desire can be prospective). Still, to be fully clear, if someone does so, then his theory is not in the category of theories discussed here.

Consider first actual desire theories according to which it is good for a person if the desires she actually has (whatever these may be and however they may have arisen) are satisfied. The more such desires are satisfied the better off she is. However, it is widely acknowledged that numerous counterexamples can be

10 Sumner $(1996,129)$ emphasizes the prospective nature of desire. Chris Heathwood $(2006 ; 2007)$ is an example of someone who insists on using the term 'desire' in a broader way such that it need not be prospective in nature but can also refer to occurrent mental states. 
generated where a person desires $\mathrm{X}$ intrinsically, gets $\mathrm{X}$, and then is, by her own lights, no better off at all. Most people intuitively respond that in such a case $\mathrm{X}$ cannot be intrinsically good for her. The intuitions are so strong that even those attracted to desire theories generally ignore actual desires.

For this reason, most philosophers interested in the desire approach have turned their attention to informed desires, namely those based on information and reflection. What they soon discover, however, is that any desire short of a fully informed desire can be used to generate counterexamples like the ones described above. For this reason most contemporary philosophers committed to desire theories embrace some form of the full information account of well-being. And it does seem that if any theory can avoid the counterexamples produced by the prospective nature of desire, this would be it. ${ }^{11}$ However, it is a highly idealized theory that equates a person's good with the desires of her hypothetical, idealized self, S+. We are to ask what $\mathrm{S}+$ (who has all the information there is to have and who is fully rational) would want for $S$ if she were to carefully consider S's position as someone about to become S (Railton 1986).

Whatever its theoretical merits, such a theory is not much use in practice. In an attempt to eliminate the problems arising from the prospective nature of desire, theorists have in effect moved to a theory that closes the gap by appealing to an omniscient version of the self. But we have no way of knowing what omniscient

\footnotetext{
${ }^{11}$ However, some theorists continue to doubt that even the full information theory will eliminate counterexamples. For critical discussions of this theory see Rosati (1995) and Sobel (1994).
} 
beings would want. And so we cannot appeal to such a theory to help us in particular cases.

Many theorists, however, are confident that there will not usually be much difference between an individual's highly idealized desires (the desires of S+) and what I shall call her "reasonably informed desires." A person has "reasonably informed desires" if she possesses a reasonable amount of the information that is both available in her world and relevant to her current choice situation, and if her desires reflect this information. Unlike fully informed desires (which no one has), many of us have reasonably informed desires and in other cases we can guess what such desires would be simply by imagining a few simple fixes to the actual desires. If it were true that the two sets of desires overlapped significantly, then one could appeal to reasonably informed desires as epistemic guides. Something like this mode of thinking may explain why some theorists are comfortable assuming something like welfare subjectivism* in practical contexts. However, it is important to remember that even if reasonably informed desires are often good guides, they are not always so, and we have no obvious ways of knowing when the two diverge. More importantly, however, there are good reasons for doubting that the two sets of desires overlap as much as some people believe.

In recent decades psychology has done much to undermine confidence in even "reasonably informed" choice. We are now more aware than ever of the multiple forms of irrationality to which all of us are prone (Kahneman 2011; Ariely 2013; Thaler 2008). Moreover, important work on affective forecasting (our ability to predict our own future emotions) has emphasized just how bad most of us are at 
imagining how we will feel in novel situations (Gilbert 2006). We are thus particularly bad at making decisions in those cases where all of our options lead us into unfamiliar territory. Yet it is significant that the choices that confront seriously ill people are often precisely of this form. Rather than fall into the habit of assuming that people are well off as long as they get what they want (or what they want when reasonably informed), we ought instead to be in the habit of asking how likely they really are to benefit if they get what they want.

Thus, as with other theories, introducing students to desire theories when we are interested in practical questions is typically unhelpful. Moreover, in the worst case it may actually serve to reinforce a way of thinking about the relationship between personal choice and welfare that, at least in the medical context, is not ideal.

\section{$\S 2.3$ Setting Aside Hedonism}

If we set aside discussion of other over-arching theories there is hardly much reason left to retain discussion of hedonism as a theory. In my experience, although people may be initially drawn to it, when forced to think about the details, most quickly reject it. Most people continue, however, to see happiness as important, even if it is not the only intrinsic value as hedonism claims. ${ }^{12}$ But given agreement that

\footnotetext{
12 It is important to distinguish the use of the term "happiness" as an evaluative term, roughly equivalent to "well-being," and use of the term in a purely descriptive, psychological sense that leaves open the relationship between happiness and well-being. I only use "happiness" in the second sense. For a detailed explanation of the difference and a defense of using the term psychologically see Haybron (2008, 29-42).
} 
happiness matters, rather than spend time debating whether it is the only intrinsic good, it makes more sense to explore what happiness is in an attempt to move past superficial understandings of it.

Not only does happiness matter, but other things do as well, and it does not take theories to get people to see this. Most people are familiar with cases where individuals voluntarily choose that which will make them less happy and where they do so for apparently self-interested reasons (for example, for the sake of some personal achievement). And reflection on such cases typically leads people to accept that there could be good choices that do not necessarily maximize future happiness.

\section{§3.0 Theory-Without-Theories}

What, then, is left? Given the way many people think about well-being, and given what I have said so far, it may seem that there is not much left to discuss or teach. But that would be premature. Philosophy and philosophical modes of thinking can do more than simply articulate and defend over-arching theories. In what follows I introduce the theory-without-theories approach which has two main components: (1) an examination of certain relatively uncontroversial elements of welfare and (2) a structural framework for thinking about the relationship between particular choices and well-being.

\section{§2.1 Illuminating Well-Being Goods and Bads}


There are some welfare values (and disvalues) that are widely accepted as such. Indeed, they are so widely accepted that we can, for practical purposes, move forward with the assumption that these things matter, and we can do so without resolving precise questions about how much they matter, whether they matter equally, whether they are the only things that matter, or whether they matter instrumentally, intrinsically, or both. The two positive values that fall in this category are psychological happiness and what I shall here call "evaluative engagement," which is active, successful engagement with the people and/or projects one cares a great deal about. The one disvalue we can be sure matters is suffering, where I take the word to indicate the more extreme forms of negative experience, including both extreme physical pain and extreme mental/ emotional distress.

By itself, the announcement that these three things are significant may strike readers as trivial. But even if most people accept that these things matter, most people have not spent much time thinking about what these things are, and the various ways in which they matter. I wish to argue that there is practical ethical value to be found in reflection on the nature of these three. Traditionally, philosophy has not just been known as a discipline devoted to constructing theories, but has also been known for its attention to and analysis of mid-level concepts or ideas, the kind of ideas that play important roles within theories. Thus one thing philosophy (here construed broadly) can do for medical ethics is to help us move towards a deeper understanding of what happiness, suffering, and evaluative engagement really are, and why they matter. 
Consider happiness first. Precisely because most ordinary people find it hard to define happiness, it can be incredibly helpful to introduce them to theories of its nature. In doing so we make it easier for them to articulate the value of happiness and of positive psychological states more generally. In ordinary thought happiness is often just defined as a "good feeling." This in turn lends support to the claim made by some theorists that psychological happiness is a trivial or shallow affair, not really worthy of our attention (Annas 2004). But there is much more to happiness than such critics allow. One of the important lessons of philosophical psychology is that complex psychological states like happiness incorporate elements of both emotion and thought. To be happy is not just to experience simple pleasure. To be happy is to have a certain (largely positive) outlook on life. On some views the defining aspect of this outlook is a judgment, for example the judgment that overall my life is going well and living up to my standards (Sumner 1996). On other views, happiness is primarily an emotional phenomenon, but one with many complex influences on our thinking (Haybron 2008).

Reflection also helps us to see that happiness is most likely valuable in more than one sense. It is plausible that it has intrinsic value (we all want to be happy independently of whether this has other good effects). But contemporary research also supports the idea that happiness is a significant instrumental good, enabling us to better realize our goals (Fredrickson 2001; Bishop 2014). By introducing people to discussions about happiness, we can improve their thinking about welfare.

Consider next, evaluative engagement. People understand instinctively that our values play an important role in our lives. The values that matter most for 
discussions of welfare are those that shape my daily life. My personal welfare is enhanced by my interactions with particular people-those I love and who love me, those I learn from, those I help, those I am friends with, and those who challenge me in various ways. And similarly my welfare is enhanced by my participation in certain projects and my pursuit of particular goals. But most people have not thought much about the ways in which realizing values over time can cause problems. ${ }^{13}$ Our values can sometimes conflict with one another in ways we fail to see. And we can have values that fail to 'fit' with our personality and so are unlikely to lead us in fulfilling directions. Thinking about such issues can deepen our appreciation of what we are aiming for when we aim to live well, and more particularly when we aim to make welfare enhancing choices. ${ }^{14}$

Finally, consider suffering. It is no surprise that suffering should be on the menu of items to discuss in medical ethics. But despite knowing that suffering is bad, many people remain unsure how to describe the difference between emotional and physical suffering, and fail to appreciate the fact that, in addition to feeling bad, suffering keeps us from appreciating and interacting with other things of value. Yet understanding the true disvalue of suffering requires understanding the many different ways it can undermine a person and her relationships to people and

13 To date the most in-depth exploration of the way values come together (or not) to inform a good life is Tiberius (2018).

${ }^{14}$ Many philosophers in one way or another address the importance of engaging values for good lives. A few examples are Kraut (1994); Darwall (2002); Raibley (2010) and (2013). To some extent the philosophical literature on meaning in life also contributes. See, e.g. Wolf (2010); and Kauppinen (2012), (2015). 
projects. It is also useful to consider reflectively the kinds of claims one sometimes encounters about the value of suffering, for it is sometimes claimed that suffering has a kind of positive instrumental value..$^{15}$ This is the theme of many popular medical biographies: "I got cancer, and then I learned what really matters"). But what precisely is it that some people "get" from negative experiences? And even if that something is good, we must be cautious about concluding that the goodness justifies the pain and loss experienced. Clearly that is not always true. Finally, it is important in the medical context to think about the complex relationships between physical pain and emotional distress (Berna et al. 2010; Fishbain 1997; Latremoliere 2009; Ploghaus 2001; Thernstrom 2010; Cassell 1991 [2004]). There is much about suffering and its role in our lives that deserves careful reflection. ${ }^{16}$

\subsection{The Mild Objectivity Framework}

In addition to examining elements of welfare, there is a second, equally important part of the theory-without-theories approach. We need, in addition, what I call the "mild-objectivity framework," which is best presented as four inter-related

${ }^{15}$ For critical discussions of this idea see Haidt (2007) and Hawkins (2018).

16 Philosophers in the analytic tradition have written a great deal about pain and significantly less about suffering. But there is still much that is important. On pain see Kahane (2016: 209-220). On suffering more generally, see e.g. Carel (2008); Green and Palpant (2014); Kauppinen (forthcoming); Hawkins (unpublished manuscript). 
assumptions to guide thinking about specific cases. These four are (1) mildobjectivity, (2) epistemic humility, (3) future truth-makers, and (4) death as deprivation.

First is the assumption of "mild objectivity." Here I do not mean what objective list theorists mean-I am not invoking the idea of value that is strongly mind-independent and/or independent of subject resonance. Here the description of the topic area as 'objective' just signals that there is room for error. In any domain where claims can be true or false, and where human beings do not have infallible access to the truth, we can speak of objective truth conditions in this mild sense. Of course, this means far less than many people realize at first. For example, one can think that claims about what is good for a particular person are objective, even while believing that the truths in question are truths about the individual's psychology and how she interacts with the world (e.g. truths about what makes her happy, what she values, and which of her values she can successfully engage with). There can be objective truths about subjective phenomena. Moreover, a commitment to mild objectivity is fully compatible with the recognition that welfare facts are individually relative, as well as compatible with the recognition that in certain cases there may be multiple, equally good answers.

All of this matters, in turn, because by adopting a mildly objective framework we can move past a number of common confusions. As mentioned earlier, many people retreat to welfare nihilism when they are unsure what to say about another person's welfare. Such a move typically results from confusing epistemic uncertainty ("I have no idea what the answer in this case is") with the metaphysical 
claim that there is no answer to be had or that all answers are equal. The mild objectivity framework substitutes instead the metaphysical assumption that there are answers, i.e. better and worse outcomes from the standpoint of the subject in question. But it also adds epistemic humility, namely an acknowledgment of the fact that it is often incredibly hard to know what the likely possible outcomes are, and therefore incredibly hard to know what a good choice would be.

Another equally common reaction to uncertainty is to retreat to the idea that an individual cannot be wrong about her own good (simple welfare subjectivism). But this confuses the thought that the subject is the authority on all aspects of her own good (which is clearly not true) with the idea that truth in this domain depends on subjective features of the person. That subjects can make mistakes seems obvious as soon as we begin to think about the ways in which even a single person can change her assessment of what is good for her over time, and how individuals themselves often view their former selves as mistaken. The mild objectivity framework emphasizes that the possibility of mistake is compatible with the thought that the truth makers of welfare claims depend on subjective features of the individual in question.

This is the relevance of the third principle: "future based truth makers." The idea here is that whether or not something is good for us depends not on what we value or want when making choices, but on how the "thing" in question affects us once we "have" it or once it enters our life. Moreover, we want to assess the relative good and bad effects of different options. In short, when we make significant welfare choices, we are making our best guess about the relative value for the subject of 
possible futures. And it is because we can so easily be mistaken about the value for a person of future options that we can so easily make poor choices.

Mild objectivity (the over-arching framework of four principles) tells us that if a person faces a choice between A and B, then in order to know what would be best for her, we need to know how she would feel about and/or react to living the life that comes with choice $\mathrm{A}$, as well as how she would feel about and/or react to living the life that comes with choice B. The better choice is the one that will have the greatest net value for her when she lives it. In keeping with the earlier discussion of welfare values, we would ask questions like this: How much happiness (if any) is likely to come from each option? How much and what type of evaluative engagement? And how much pain or suffering is likely to come from each option (if any)? The best choice is the one that, as best we can tell on the basis of our evidence, leads to the future with the greatest net value for the individual. ${ }^{17}$

Of course, in a great many cases we do not have enough information to make fine-grained distinctions among possible options. Moreover, the framework is not designed to enable us to do so even in theory. But we do not need such precise judgments. What we want and what the framework offers us is a way to identify cases where it seems that someone is about to choose something that will be much worse for her than other available alternatives. This is sufficient in the context of clinical medicine, since it is only when a patient's choice appears to be quite bad and avoidably so that it makes sense to converse more about the options, and perhaps

\footnotetext{
17 I have discussed issues related to this thesis-what I here call "future-based truth makers" in several other publications. See Hawkins (2014; 2019a; 2019b).
} 
even try to rationally persuade the patient to choose differently. Thus if a person appears to be making a choice that will leave them much less happy than they could be, without, so far as one can see, any compensating gains in terms of evaluative engagement, this is very likely a poor choice. The reverse is also true, namely, if a person appears to be choosing something that will limit her evaluative engagement much more than other options she has, with no apparent compensation in terms of increased happiness or reduced stress etc., then this is very likely a poor choice. And finally if a patient seems to be choosing something that will come at the cost of great, protracted suffering or which will end her life, when there exist for her other options free of such suffering and which contain many welfare goods, this too seems like a very poor choice and an excellent time for further discussion.

The final element in the framework is the deprivation account of the badness of death (Kagan 1997; Feldman 1992). I include this because students are often confused about how to factor the goodness or badness of death into a welfare framework. But since many cases discussed in bioethics involve life and death choices, it is important for people to have a way of conceptualizing this. The basic idea is that in order to understand when death is bad for a person, we must compare the life that person would have led if she died right now, and the longer life she would lead if she continued to live longer. If the net value of the longer life is greater than the net value of the shorter one, then it is better for the person not to die now, but to live out the additional segment of life. If on the other hand the net value of the shorter segment is greater, then death now is not really a harm. 


\section{$\S 3.3$ Illustrating the Value of the Theory-without-Theories Approach}

The mild objectivity framework can deepen our appreciation of many types of cases, helping us to think better than we do when we simply rely on welfare subjectivism. Consider, for example, cases in which a person must decide whether it is worthwhile to re-build a life altered irrevocably by accident or illness. In such cases, exclusive reliance on the patient's current values may not be particularly illuminating and may even be bad. To see why consider the following fictional case. ${ }^{18}$

Dave was an avid hunter who was in a tree one day watching for deer when he startled at the sound of another hunter's gun, fell 16 feet to the ground and severely damaged his spine. When paramedics arrived they sedated him, and he remained sedated once he arrived at the hospital. Physicians quickly tried to determine the extent of his injury. It soon became clear that he would likely be paralyzed from the chest down (a C4 injury), ${ }^{19}$ though it remained unclear whether he would ultimately be ventilator dependent. Significantly, however, he was at that moment ventilator dependent.

Dave's family reported that Dave had always valued an active life. They felt that if he had been asked before his accident whether he would want to live as a

\footnotetext{
${ }^{18}$ Although fictional in the sense that I have filled in details of my own invention, the case is based on a story reported by CBS News November 6, 2013. Available at https://www.cbsnews.com/ news/paralyzed-hunter-chooses-to-be-taken-off-life-support/. Accessed Monday April 23, 2018.

${ }^{19}$ Cole (2004) explains that anyone with C4 injury or higher is quadraplegic, but that someone with a C4 injury "may be able to breathe unaided using the diaphragm, though he or she will still have lost chest wall movement and will have reduced expansion of the lungs." Jonathan Cole, Still Lives: Narratives of Spinal Cord Injury (Cambridge, MA: MIT Press), p.14.
} 
paralyzed person he would have said no, and for this reason his family asked that he be removed from the ventilator and allowed to die. However, the doctors involved rightly insisted that that had to be Dave's choice. What they did next, however, was unusual. They brought Dave out of sedation and asked him right then whether he wished to live as a paralyzed person. He had only been awake and aware of his diagnosis a short time when he made his decision. He echoed the views his family had ascribed to him, asking to be taken off the respirator. Because he was so clear about what he wanted, the ventilator was turned off and he died very shortly after his accident and only a few hours after learning his diagnosis. What is unusual is not that his wishes were honored but that they were honored so soon after his accident, as well as the fact that no one tried to educate him about disability or explain to him what his life as a paralyzed individual could be like.

In my experience many students are initially comfortable with the outcome of this case. When pushed to say why, they cite the fact that he acted on values he had had for a long time. When the possibility of mistake is raised they are at first skeptical that any mistake could exist here.

However, there are good reasons in this case for thinking that Dave chose badly even though he got exactly what he asked for. There is much empirical evidence to suggest that although people with severe spinal cord injury initially want to die or feel despairing about the future, they go on (once they adapt a bit) to value their lives. The empirical evidence for this is amazingly strong (Chwalisz et al., 
1988; Lundqvist et al, 1991; Cushman \& Hassett, 1992; Whiteneck et al, 1992).20 Since all of the paralyzed individuals in the studies cited here once thought as Dave did, the mere fact that he valued active life at the time of his accident and was convinced that he could not be happy as a paralyzed person is not sufficient to tell us whether that is true. The evidence we have suggests that Dave is very likely making a mistake. However, epistemic humility requires us to also acknowledge that Dave is an individual and we simply don't know how he might have felt had he lived longer.

Importantly, in the process of thinking about the case, students generally shift their sense of what would convince them of the truth of various claims. They come to appreciate that what matters is not what Dave says when he wakes up, but what would actually have happened if he had lived. They come to think in terms of "future based truth makers." Some students remain convinced that Dave's personality (as revealed by what we know of his actions and values) is such that he really could not have been happy as a disabled person. But even these students typically grant that his choice would be a prudential mistake if it were true that if he had lived he would have derived significant benefit from his extended life.

\footnotetext{
20 The citations in the text report no relevant difference in well-being between spinal cord injured (SCI) persons and non-disabled controls. Other studies have found lower quality of life among SCI persons, but interestingly only a little lower (P. Brickman, et. al. 1978; R. Schulz \& S. Decker, 1985; R. Stensman, 1994; M. Kannisto \& H. Sintonen, 1997; Marcel Dijkers, 1997). Furthermore, many other studies support the idea that the primary explanations of differences are social and not degree of impairment (R. Schulz \& S. Decker, 1985; Chase et al., 2000; I. Ville \& J.F. Ravaud, 2001).
} 
My aim in teaching the case is not to convince students that Dave make a mistake. Rather, I want them to take seriously the idea that there are better and worse outcomes, and that therefore mistake is a real possibility. I also want them to think about the kinds of evidence that might support one or another view of how things might go, and to see that at least sometimes the evidence points strongly in one direction or another. This matters because once they accept the possibility of error, they see that much more could and should be done in a case like Dave's before simply acquiescing with his wish to die. Ultimately, of course, the choice is his. But someone should at least talk to him about it once he is no longer in shock. And someone should educate him about his disability and how others with similar disabilities live. In short, framing the situation in mildly objective terms changes the way students see the conversational obligations of healthcare providers.

As a further illustration of the power of the framework, consider a very different case described by Atul Gawande in his book Complications (2002). In a chapter entitled, "Whose Body Is It Anyway?" Gawande sets out to document the radical changes in medical decision-making that have occurred since the 1970s and to emphasize that even though patients are now in charge, patients do not always choose well. The primary example that runs through the essay involves a patient Gawande calls "Lazaroff."

Lazaroff is dying of cancer and there is nothing that can be done about it. All that is at issue is what sorts of symptom-related treatments he might choose during his last months. His legs are becoming paralyzed because of a tumor pressing his spine. There is a surgery that might halt the paralysis, but he is already so fragile 
that he is highly unlikely to recover from it. If he chooses surgery, the odds are high that he will die in the ICU in great pain and hooked up to many machines. To make this concrete and vivid let us assume that if he chooses surgery it is $90 \%$ likely that he will either die in surgery or die an ICU death. This means there is only a $10 \%$ chance of Lazaroff surviving the surgery, avoiding the ICU, and going home to enjoy his last few months without paralysis. The alternative is to go home now, without surgery, and receive comfort care allowing the paralysis to remain. He has stated in the past that he doesn't want to die in the ICU because he watched his wife die this way. Yet now Lazaroff chooses surgery and, predictably, he dies after two weeks in the ICU, in great pain and hooked up to many machines.

Gawande presents this case from the outset as a case of poor decisionmaking. But what is interesting is how he argues for this. He is careful to emphasize that Lazaroff had always wanted to avoid an ICU death. This is represented as Lazaroff's stable, deep desire. Opting for the surgery, on the other hand, is presented as a rash decision made during an emotional moment (It is made in the presence of his son as part of an attempt not to appear passive, but to seem to be "doing" everything possible to "fight" the illness). If that is the right description, then this is a case where momentary emotion leads a person to act in a way that goes against what he currently values most and is thus a perfect illustration of the kind of case described by Brock and Wartman. However, as with Brock and Wartman's article, presenting mistakes this way reinforces the idea that patient values determine welfare (welfare subjectivism*). Lazaroff made a mistake because he failed to get what he really wanted. 
But why do we need to assume that Lazaroff really had an enduring desire to avoid the horrible ICU death described by Gawande in order to see him as making a mistake by choosing it? Presumably the choice would be just as bad in a slightly different scenario. Imagine a man who has not witnessed his wife or anyone else die in the ICU and so currently has no particular attitudes towards such an outcome. This man has not generally been the kind of person who adopts an aggressive "fight with everything you have" mentality in response to life crises. Still, when he develops cancer, he encounters many examples of such an attitude towards the illness, and he comes to think this is a good attitude to take. He is currently suffering a great deal psychologically and struggling to accept that he is dying. When presented with the option of the surgery he decides (in keeping with his new "fight" values) to opt for it.

Even though in this case he chooses what he currently most wants in a robust sense of want (there is here no hint that the choice stems from a transient emotional reaction), it is still doubtful that his new values are serving him well. Whether they are depends on facts about his personality, which in turn shape how he will actually react if things go badly. But since many (perhaps even most) patients do not react well to such experiences, it still seems reasonable to try and convince a patient to forgo a surgery with such high odds of a grim death.

According to the mild objectivity framework, what underwrites the reader's conviction that Lazaroff chose badly is not what we know about his values presurgery, but rather what we know about (1) how he actually died (he is described as suffering terribly, where I assume this includes not just pain, but psychological 
suffering as well), and (2) what we assume are the facts about what would have happened if he had chosen differently. If he had not opted for the surgery, he would have lived a bit longer, though with increasing leg paralysis. He could have died at home without pain when the time came. Of course, it is true that he might never have fully accepted his imminent death and he might have continued to be made unhappy by the paralysis. We shouldn't naively assume that the last months at home would necessarily be good. But even so, it is plausible that his overall experience going forward without surgery would be better than the experience he ultimately had. As with the case of Dave, one benefit of approaching the case this way is that students then focus on what might have been done to help Lazaroff avoid such a mistake.

The mild objectivity framework can also be used to illustrate the importance of certain distinctions, such as the distinction mentioned earlier between medical values and welfare outcomes. Precisely because medical values so often serve patient welfare, it can be tempting to revert to a welfare medicalism framework when confronted with difficult cases. But the theory-without-theories approach, and in particular the mild objectivity framework, offers a useful alternative that emphasizes the variety of ways medical values can serve (or fail to serve) overall welfare.

Consider, for example, the rare case of patients with Body Integrity Identity Disorder (BIID) who strongly feel that one of their limbs is not really theirs and who desperately want someone to surgically amputate the otherwise healthy limb (Bayne and Levy 2005). Taking such cases seriously requires being at least willing 
to consider whether amputation might in fact be the best option for such patients. But because removing a healthy limb is so contrary to what doctors typically doone could call it a medical anti-value-many people initially react by insisting that it simply can't be good for a person to lose a limb. Others take the opposite view that amputation is justified because this is what these patients most want.

However, what we really need to know are things such as (1) whether there are any non-surgical options that would leave such patients feeling better and (2) if not, whether surgery would really make them better overall than they are currently. Of course the patients believe that the only possible way to improve their lives is to amputate the limb. But what we want to know is whether they are right.

Once again this seems to depend on comparative facts about potential outcomes. For example, if it turned out that after having a limb amputated a person simply transferred her concern to a new limb, wanting it removed, and continuing to feel miserable, then the original surgery would have caused disability (which is, at least somewhat negative, since it will come with at least some limitations that require adjustment) without any compensating improvement in terms of greater happiness, greater engagement, or less suffering. The framework emphasizes (as seems right) that the truth about what would be best for such patients depends on future facts about relative welfare, and not simply on what the patient wants, or what doctors typically do.

Or consider a much less dramatic case: Most people these days automatically and unreflectively think of smoking as a deeply unhealthy activity—an activity that a doctor should never recommend. Like healthy limb amputation it may be best 
characterized as a medical anti-value. However, for a patient with incurable lung cancer it might be good to smoke, particularly if it is unlikely to shorten his life any more than it already has been by the cancer and if the effort to stop is making him miserable. In short, once it is true that the values usually served by non-smoking are no longer attainable for this person, it may be best for his overall welfare to smoke. And in some cases it may even be appropriate for his doctor to say so (Ubel 2012).

Finally, I believe that it is only by framing things in terms of mild objectivity and better and worse answers that certain kinds of familiar ethical debate can be presented in ways that really make sense. For example, it is difficult to properly grasp the dilemma posed by medical paternalism unless one first sees that there might be a case where a patient is wrong and a physician right about what would be best for the patient and where the consequences of non-interference are dire. One need not suppose that such cases are common. But all too often in medical ethics the moral issues of paternalism are glossed over. A simplistic story is told according to which doctors used to be paternalistic (which is true) and used to make decisions for patients according to welfare medicalism (which is also mainly true). But then there was a patient's rights movement, choice was given to patients, and all was well. Simple welfare subjectivism triumphed over welfare medicalism.

On that picture it is hard to see why there was ever much moral debate about paternalism. On this picture paternalism frequently harms patients, and the alternative-letting the patient choose- is always beneficial, or at least almost always so. There is no real tug of values here. 
However, it is precisely because both patients and doctors can be wrong about what would be best, and because it is incredibly hard for many clinicians to stand by and watch individuals make what seem to be (and in some cases very likely are) self-destructive choices, that paternalism remains a moral temptation. A true anti-paternalist is someone who has confronted the real range of possibilities-who sees that the weight of reasons support non-intervention-but grasps that commitment to anti-paternalism means she may have to allow someone to seriously and irrevocably harm himself.

The Dave case and the Lazaroff case are good illustrations of this, since most students allow that it is possible Dave is making a mistake, and likewise most readers view Lazaroff as making one. Both cases lead students to want to talk more with the patients in question: to educate them further and make sure they truly grasp what they are rejecting or choosing. But we cannot simply assume in either case that the patient will change direction based on more conversation or explicit advice. Whether or not they do, the choice is still theirs to make. Nonetheless, such cases provide excellent opportunities for considering paternalism in all its complicated reality. Such cases illustrate that real values are at stake either way, and that the choice to refrain from paternalism, even if best overall, is not cost-free.

\section{§4.0 Conclusion}

Medical ethics needs a more sophisticated, nuanced approach to thinking about the well-being of patients. But as I have tried to show, introducing philosophical theories of well-being into medical ethics discussions is not helpful and often 
counter-productive. This does not mean, however, that philosophy has no role to play. It does. I have here outlined what I call the theory-without theories approach, which focuses on analyzing important, relatively uncontroversial aspects of welfare, and framing discussion of clinical cases and good clinical choice in terms of the mild objectivity framework. It is a philosophical approach to well-being that tries to get as much mileage as possible from ideas about well-being that are widely (though not universally) agreed upon. But it is not a theory of well-being.

Throughout the paper, I have for the most part emphasized the ways in which the theory-without-theories model can improve medical ethics teaching. But it was never my intention to suggest that that is its only use. I genuinely believe that medical ethics scholarship would also be better if it incorporated this model or something much like it. This is because medical ethics scholarship would benefit from more frequent and more explicit discussions of patient welfare. But this, in turn, will only be really helpful if scholars can manage to avoid problematic simplifications such as welfare nihilism or welfare subjectivism, on the one hand, and reliance on controversial philosophical theories. such as objective list theories, on the other. Finally, if better thinking about well-being were to become a part of both medical ethics teaching and scholarship, it might also eventually help to improve real-life conversations between doctors and patients. And that is pretty much the best outcome ethicists can hope for.

\section{References}

Annas, J. 2004. Happiness as achievement. Daedalus 133: 2: 44-51. 
Ariely, D. 2010. Predictably Irrational: The Hidden Forces That Shape Our Decisions, revised and expanded edition (New York: Harper Perennial).

Bayne, T. and Levy N. 2005. "Amputees by Choice: Body Integrity Identity Disorder and the Ethics of Amputation." Journal of Applied Philosophy 22 (1): 75-86.

Beauchamp, T. L. and Childress J. F. 1994. Principles of Biomedical Ethics, 4th ed. (New York: Oxford University Press).

- - 2012. Principles of Biomedical Ethics, 7th ed. (New York: Oxford University Press).

- - - and Walters L., Kahn J. P., and Mastroianni A. C. (eds.) 2013. Contemporary Issues in Bioethics 8th edition. (Boston, MA: Wadsworth Cengage).**

Berna C., and Leknes S., Holmes E. A., Edwards R. A., Goodwin G. M., Tracey I. 2010. Induction of depressed mood disrupts emotion regulation neurocircuitry and enhances pain unpleasantness. Biological Psychiatry 67: 11: 1083-1090.

Bishop, M. 2014. The Good Life: Unifying the Philosophy and Psychology of WellBeing (Oxford: Oxford University Press).

Bradford, G. 2017. "Perfectionism." In: Guy Fletcher ed. The Routledge Handbook of Philosophy of Well-Being. (New York: Routledge) 124-134.

Brickman, P. and Coates D., Janoff-Bulman R. 1978. Lottery winners and accident victims: Is happiness relative? Journal of Personality and Social Psychology 36: 8: 917-27.

Brock, D. W. and Wartman S. A. 1990. When competent patients make irrational decisions. New England Journal of Medicine 322:22: 1595-99.

Carel, H. 2008. Illness. (Durham, UK: Acumen Publishing).

Cassell, E. J. 2004 [1991]. The Nature of Suffering and the Goals of Medicine 2nd ed. (New York: Oxford University Press).

Chase, B. W. and Cornille T. A., English R. W. 2000. Life satisfaction among persons with spinal cord injuries. Journal of Rehabilitation 66: 3: 14-20.

Chwalisz, K. and Diener E., Gallagher D. 1988. Autonomic arousal feedback and emotional experience: evidence from the spinal cord injured. Journal of Personality and Social Psychology 54: 5: 820-8.

Cushman, L. A. and Hassett J. 1992. Spinal cord injury: 10 and 15 years after. Paraplegia 30: 10: 690-96. 
Darwall, S. 2002. Welfare and Rational Care. (Princeton, NJ: Princeton University Press).

DeGrazia, D. 1995. Value theory and the best interest standard. Bioethics 9: 1: 50-61.

_-_— and Mappes T., Ballard, J. (eds). 2011. Biomedical Ethics 7th edition (New York: McGraw Hill).**

Dijkers, M. 1997. Quality of life after spinal cord injury: A meta-analysis of the effects of disablement components. Spinal Cord 35: 12: 829- 40.

Emanuel, E. J. and Emanuel, L. L. 1992. Four models of the physician-patient relationship. Journal of the American Medical Association 267: 16: 2221-26.

Fishbain, D. A. and Cutler R., Rosomoff, H. L., Rosomoff, R. S. 1997. Chronic Pain Associated Depression: Antecedent or Consequent of Chronic Pain? A Review. Clinical Journal of Pain 13: 2: 116-37.

Fredrickson, B. L. 2001. The role of positive emotions in positive psychology: the broaden and build theory of positive emotions. American Psychologist 56: 3: 218-26.

Gawande, A. 2002. Whose body is it anyway? In: Complications: A Surgeon's Notes On an Imperfect Science. (New York: Metropolitan Books).

Gilbert, D. 2006. Stumbling on Happiness (New York: Knopf).

Griffin, J. 1986. Well-Being: Its Meaning, Measurement and Moral Importance. (Oxford: Oxford University Press).

Green, R. M. and Palpant N. J. (eds). 2014. Suffering and Bioethics. (New York: Oxford University Press).

Groll, D. 2016. Medicine and well-being. In The Routledge Handbook of the Philosophy of Well-Being, (ed.) G. Fletcher (New York: Routledge), 504-16.

Haidt, J. 2006. The Happiness Hypothesis: Finding Modern Truth in Ancient Wisdom. (New York: Basic Books).

Hall, A. 2016. Making good choices: toward a theory of well-being in medicine. Theoretical Medicine and Bioethics 37: 383-400.

Hawkins, J. 2014. “Well-Being, Time, and Dementia." Ethics 124: 507-542.

_-_2018. Artistic creativity and suffering. In Creativity and Philosophy, (eds.) 
B. Gaut and M. Kieran. (New York: Routledge), 152-69.

_-_ 2019a. "Internalism and Prudential Value." Oxford Studies in Metaethics, Volume 14. Ed. Russ Shafer-Landau. (New York: Oxford University Press), 95-120.

_-_ 2019b. "Well-being, the Self, and Radical Change." Oxford Studies in Normative Ethics, Volume 4. Ed. Mark Timmons. (New York: Oxford University Press), 251-270.

_- - 2019c. "Diversity of Meaning and the Value of a Concept: Comments on Anna Alexandrova's A Philosophy for the Science of Well-Being." Res Philosophica 96: 4: 529-535.

-_-Unpublished manuscript. "Suffering as Perspective: On the Nature and Badness of Suffering."

Haybron, D. M. 2008. The Pursuit of Unhappiness: The Elusive Psychology of WellBeing. (New York: Oxford University Press).

Haybron, D. M. and Tiberius V. 2015. Well-being policy: What standard of wellbeing? Journal of the American Philosophical Association 1:4: 712-33.

Heathwood, C. 2006. "Desire Satisfactionism and Hedonism." Philosophical Studies 128: 539-563.

_-_ 2007. "The reduction of sensory pleasure to desire." Philosophical Studies, 133: 23-44.

Johnson, A. R. and Siegler M., Winslade W. J. (eds). 2015. Clinical Ethics: A Practical Approach to Ethical Decisions in Medicine, 8th Edition (New York: McGrawHill Education).**

Kagan, S. 2009. "Well-being as enjoying the good." Nous Supplement: Philosophical Perspectives 23: 253-272.

Kahane, G. 2017. "Pain, Experience, and Well-Being." In: Guy Fletcher (ed.) The Routledge Handbook of Philosophy of Well-Being. (New York: Routledge), 209-220.

Kahneman, D. 2011. Thinking Fast and Slow (New York: Farrar, Straus and Giroux).

Kannisto, M. and Sintonen H. 1997. Later health-related quality of life in adults who have sustained spinal cord injury in childhood. Spinal Cord 35: 11: 747-51. 
Kauppinen, A. 2012. "Meaningfulness and Time." Philosophy and Phenomenological Research 84 (2): 345-377.

_- - 2017. "Meaningfulness" In: Guy Fletcher (ed.) The Routledge Handbook of Philosophy of Well-Being. (New York: Routledge), 281-291.

-_- Forthcoming. "The World According to Suffering." In: The Philosophy of Suffering, (eds.) D. Bain, M. Brady, and J. Corns. Routledge.

Kraut, R. 1994. "Desire and the Human Good." Proceedings and Addresses of the American Philosophical Association 68: 39-54. Reprinted in: Morality and the Good Life. (eds.) T. Carson and P. Moser (New York: Oxford University Press, 1997).

Kuhse, H., and Schuklenk U., Singer P. (eds). 2015. Bioethics: An Anthology, 3rd edition. (Malden, Ma.: Wiley-Blackwell).**

Latremoliere, A., and Woolf C. J. 2009. Central sensitization: A generator of pain hypersensitivity by central neural plasticity. Journal of Pain 10: 9: 895-926.

Lundqvist, C. and Siosteen A., Blomstrand C., Lind B., Sullivan M. 1991. Spinal cord injuries: Clinical, functional, and emotional status. Spine, 16: 1: 78-83.

Munson, R. and Lague I. (eds). 2016. Intervention and Reflection: Basic Issues in Bioethics, 10th edition (Boston, Ma.: Cengage Learning).**

Parfit, D. 1984. Reasons and Persons. (Oxford: Clarendon Press).

Pierce, J. and Randels G. (eds). 2009. Contemporary Bioethics: A Reader with Cases (New York: Oxford University Press).**

Ploghaus A, and Narain C., Beckmann C. F., Clare S., Bantick S., Wise R., Matthews P. M., Rawlins N. P., Tracey I. 2001. Exacerbation of pain by anxiety is associated with activity in a hippocampal network. Journal of Neuroscience 21: 24: 9896-9903.

Raibley, J. 2010. "Well-being and the Priority of Values." Social Theory and Practice 36 (4): 593-620.

_-_2013. "Values, Agency, and Welfare." Philosophical Topics 41 (1): 187-214.

Railton, P. 1986. “Facts and Values," Philosophical Topics 14 (2): 5-31.

Rosati, C. S. 1995. "Persons, perspectives and full information accounts of the good," Ethics 105:2: 296-235. 
Savulescu, J. 2007. Autonomy, the good life and controversial choices. In The Blackwell Guide to Medical Ethics, (eds.) R. Rhodes, L. Francis, and A. Silvers. (New York: Blackwell).

- - 1995. Rational non-interventional paternalism: why doctors ought to make judgments of what is best for their patients." Journal of Medical Ethics 21:6: 327-31.

Schulz, R. and Decker S. 1985. Long-term adjustment to physical disability: The role of social support, perceived control, and self-blame. Journal of Personality and Social Psychology 48: 5: 1162-72.

Singer, P. A. and Viens A. M. (eds). 2008. The Cambridge Textbook of Bioethics (Cambridge: Cambridge University Press).**

Sobel, D. 1994. Full information accounts of well-being," Ethics 104: 784-810.

Steinbock, B. and London A. J., Arras J. (eds.) 2013. Ethical Issues in Modern Medicine: Contemporary Readings in Bioethics, 8th edition. (New York: McGraw Hill).**

Stensman, R. 1994. Adjustment to traumatic spinal cord injury: A longitudinal study of self-reported quality of life. Paraplegia 32: 6: 416-22.

Sumner, L. W. 1996. Welfare, Happiness and Ethics. (Oxford: Oxford University Press).

Thaler, R. H. and Sunstein C. R. 2008. Nudge: Improving Decisions about Health, Wealth, and Happiness (New Haven: Yale University Press).

Thernstrom, M. 2010. The Pain Chronicles: Cures, Myths, Mysteries, Prayers, Diaries, Brain Scans, Healing and the Science of Suffering. (New York: Picador).

Tiberius, Valerie. 2018. Well-Being as Value-Fulfillment: How We Can Help Each Other to Live Well. (Oxford: Oxford University Press).

Ubel, P. A. 2012. Critical Decisions: How You and Your Doctor Can Make the Right Medical Choices Together. (New York: Harper Collins).

Vaughn, L. (ed). 2016. Bioethics: Principles, Issues and Cases, 3rd edition. (New York: Oxford University Press).**

Ville, I. and Ravaud J. F. 2001. Subjective well-being and severe motor impairments: The tetrafigap survey on the long-term outcome of tetraplegic spinal cord injured persons." Social Science and Medicine 52: 3: 369-384.

Whiteneck, G. G. and Charlifue S. W., Frankel H. L., Fraser M. H., Gardner B. P., 
Journal of Medicine and Philosophy, forthcoming 2021

Gerhart K. A., Krishnan K. R., Menter R. R., Nuseibeh I., Short D. J., Silver J. R. 1992. Mortality, morbidity, and psychosocial outcomes of persons spinal cord injured more than 20 years ago. Paraplegia 30: 9: 617-630.

Wolf, S. 2010. Meaning in Life and Why it Matters. (Princeton, NJ: Princeton University Press). 